\title{
Population Dynamics of Synanthropic Rodents After a Chemical and Infrastructural Intervention in an Urban Low-income Community
}

Adedayo Michael Awoniyi

Federal University of Bahia

Cristina Venegas-Vargas

Michigan State University

Fabio Neves Souza

Federal University of Bahia

Caio Graco Zeppelini

Federal University of Bahia

Kathryn P. Hacker

University of Michigan

Ticiana Carvalho Pereira

Federal University of Bahia

Catarina Lobo Marins

Federal University of Bahia

Mayara Carvalho de Santana

Fundação Oswaldo Cruz, Ministério da Saúde

Arsinoê Cristina Pertile

Federal University of Bahia

Mike Begon

University of Liverpool

Albert I. Ko

Yale University

Peter Diggle

Lancaster University

Mitermayer Galvão dos Reis

Federal University of Bahia

James E. Childs

Yale University

Eduardo Mendes da Silva

Federal University of Bahia

Federico Costa 
Federal University of Bahia

Hussein Khalil ( $\square$ hussein.khalil@slu.se)

Swedish University of Agricultural Sciences (SLU)

\section{Research Article}

Keywords: Integrated Pest Management (IPM), Low-income communities, Rat infestation, Rodent control, Rodenticides

Posted Date: January 27th, 2022

DOI: https://doi.org/10.21203/rs.3.rs-1195833/v1

License: (9) This work is licensed under a Creative Commons Attribution 4.0 International License. Read Full License 


\section{Abstract}

Synanthropic rodents are ubiquitous in low-income communities and pose risks for human health, as they are generally resistant to control programs. However, few or no studies have evaluated the long-term effect of chemical and infrastructural interventions on rodent population dynamics, especially in urban low-income communities, or evaluated the potential recovery of their population following interventions. We conducted a longitudinal study in a low-income community in the city of Salvador (BA, Brazil) to characterize the effect of interventions (chemical and infrastructural) on the dynamics of rodent population, and documented the post-intervention recovery of their population. We evaluated the degree of rodent infestation in 117 households/sampling points over three years (2014 - 2017), using tracking plates, a proxy for rodent abundance/activity. We reported a significant lower rodent activity/abundance after the chemical and infrastructural interventions $(\mathrm{Z}=-4.691(\mathrm{p}<0.001))$, with track plate positivity decreasing to $28 \%$ from $70 \%$ after and before interventions respectively. Therefore, the combination of chemical and infrastructural interventions significantly decreased the degree of rodent infestation in the study area. In addition, no rodent population rebound was recorded until almost a year post-intervention, and the post-intervention infestation level did not attain the pre-intervention level all through the study. Moreover, among pre-treatment conditions, access to sewer rather than the availability of food was the variable most closely associated with household rodent infestation. Our study indicates that Integrated Pest Management (IPM)-approaches are more effective in reducing rodent infestation than the use of a single method. Our findings will be useful in providing guidance for long-term rodent control programs, especially in urban low-income communities.

\section{Introduction}

Rodents are highly adaptable animals, capable of colonizing human-altered environments, and can rapidly establish large populations where abundant resources are available, e.g. in urban low-income communities ${ }^{1}$. Synanthropic rodents are considered pests given their negative impacts on human health and economy ${ }^{2-4}$. Specifically, rats are reservoirs for several important viral, bacterial and parasitic diseases, which have likely caused more human casualties than wars ${ }^{5-9}$. Likewise, rodents destroy and contaminate agricultural products and infrastructure worth billions of dollars per year, while their sightings affect residents' mental health ${ }^{9}$.

Urban low-income communities typically provide the environmental conditions that promote the proliferation of rodents ${ }^{10-12}$, which in turn complicates the management of their populations in these environments ${ }^{13}$. For instance, inadequate housing and sanitation (e.g. open sewers) and lack of adequate garbage collection services promote rodent presence ${ }^{12}$, and these are expected to worsen globally given the expected increase in the population of low-income community dwellers from the 751 million recorded in 1950 to more than 3 billion by $2050^{14}$. Also, it is estimated that 1 in every 4 people will either reside in informal settlements or require adequate and affordable housing by $2030^{15}$. Therefore, urban population increase will likely stress the local infrastructure further, especially in developing and 
under-developed countries, thereby leading to higher rodent proliferation and thus, more frequent humanrodent interactions.

Rodent control is one of the main public health measures implemented in urban poor communities, mainly to reduce the risk of disease transmission ${ }^{3}$. The methods applied are mainly chemical, using rodenticides with immediate short-term effects in the population ${ }^{3,5,16}$. However, several other interventions can be implemented simultaneously for longer-lasting effects. Non-chemical methods include closing of open sewer canals and regular solid waste collection ${ }^{17}$; hunting, trapping, capturing and other physical removal methods ${ }^{18,19}$; movement barriers and environmental modifications (e.g. electric fencing, pavement) ${ }^{20,21}$; likewise biological control using pathogens or predatory animals ${ }^{22-26}$. The paradigm of Integrated Pest Management (IPM) that recommends the use of several methods together has been adopted in several urban centers, with mixed results ${ }^{27}$.

Rodent infestations are difficult to control and/or manage, since the surviving population can rapidly recover through reproduction ${ }^{28}$ or immigration ${ }^{6}$. Following a period of population decline, rats can travel up to 90 meters even in a heterogeneous urban environment ${ }^{23,29,30}$, and repopulate the area. Rodent control is especially difficult in urban environments due to the heterogeneity of the urban environment and because most control methods have been developed for rural or agricultural settings. Non-chemical methods also tend to have practical setbacks; for example, physical removal of rodents is time and labour-intensive, environmental modifications are expensive and labour-intensive, while electric fencing and inhibition of reproduction are non-species specific and could affect humans and other non-target species alike. As a result, lethal chemical agents remain the main method employed during rodent control programs in urban areas ${ }^{31,32}$. Rodenticides are somewhat effective in controlling populations three months post-intervention ${ }^{10,33}$. However, the long-term efficacy of a combination of chemical and infrastructural interventions on the dynamics of rodent populations, as well as the time lag between control deployment and the onset of rodent repopulation, are not clear.

Here, a case-control study was performed in Pau da Lima, an urban poor community in the periphery of Salvador, Brazil ${ }^{34}$. Pau da Lima consists of four valleys with similar environmental conditions that support relatively large rodent populations ${ }^{11}$. Three valleys (1,2 and 4) with apparent signs of rodent infestation out of the four valleys were used for this study. The three valleys had concurrent infrastructural and chemical interventions. However, while the infrastructural intervention took place across all valleys, chemical intervention occurred only at valleys 1 and 4 (hereby referred to as the treatment valleys), while valley 2 received no chemical intervention and served as the control valley.

For the first time, we followed up with the trends in rodent infestation before and after interventions over a long-term period even in a tricky urban terrain such as Salvador, and evaluated 1) whether the combination of chemical and non-chemical interventions is indeed effective in the long-term control of rodent populations; 2 ) the timeline potentially required by the rodent population to return to their initial population abundance after interventions; and 3) the environmental and peri-domestic factors that are 
associated with rodent population rebound in the three valleys. Therefore, unlike previous studies ${ }^{32,33}$ that only evaluated rodent infestation before and six months after intervention, this study offers the most comprehensive longitudinal study on how rodent populations respond to chemical and non-chemical interventions in a complex urban environment such as Salvador.

\section{Methods}

\section{Study area}

Pau da Lima ( $13^{\circ} 32^{\prime} 53 \cdot 47^{\prime \prime} \mathrm{S} ; 38^{\circ} 43^{\prime} 51 \cdot 10^{\prime \prime} \mathrm{W}$ ), is a low-income urban community (area. $0.17 \mathrm{~km}^{2}$ ) with about 128,997 inhabitants ${ }^{35}$. The community is characterized by inadequate housing facilities, poor basic social amenities, unsatisfactory sanitation system i.e. open sewers, improper garbage disposal and deficient garbage collection services with a history of household rodent infestation ${ }^{11}$. We conducted our study in three valleys (valleys $1,2 \& 4$ ) that have been previously described by Panti-May et al. ${ }^{1}$ (Fig. 1A).

\section{Sample size and frequency}

One-hundred and twenty sampling points were randomly selected from the longitudinal study monitoring the urban rodents in Salvador, Brazil. However, we excluded 3 sampling points due to inaccessibility. These 117 points were randomly selected from the three valleys (Fig. 1A), with 46 sampling points from valley 1,38 from valley 2 and 33 from valley 4 , respectively.

The longitudinal sampling occurred over three years (2014 - 2017), and the surveys were divided into a total of 7 campaigns (" $\mathrm{C} 1$ " through " $\mathrm{C7}$ ") in all valleys, with each campaign lasting 3-4 months as shown in figure 1B. Also, the surveys were divided into two phases, pre-intervention (C1 \& C2) and chemical \& infrastructural - post-intervention (C3 - C7) (see Fig. 1B).

\section{Interventions}

Chemical intervention Valleys 1 and 4 served as the treatment and received chemical intervention (rodenticides), while valley 2 was considered as the control and received no chemical intervention. Using the United States' Center for Disease Control and Prevention, $\mathrm{CDC}^{36}$ guidelines for interior and exterior rodent inspection, we identified, through rodent signs such as burrows, trails, or feces, active rodent spots at sampling points in both valleys 1 and 4 . At each sampling point, trained staff of the Center for Control of Zoonoses (Centro de Controle de Zoonoses - CCZ) applied anticoagulant rodenticides (paraffin blocks and contact powder) within households and in peri-domestic areas in early September 2015, shortly before the first post-intervention campaign (C3). Before the initiation of the intervention, residents were duly informed of the purpose of the study and the necessary procedures required in dealing with rodents during the study period.

Also, the residents were educated about the importance of using appropriate waste disposal; putting waste out at collection points on the morning/evening of collection instead of a few days before 
collection; keeping pets' food out of rodents' reach, and the need to reduce or obstruct other sanitationrelated means by which rodents could gain access to food and/or water.

The formulations used for the chemical intervention were: paraffin block (brodifacoum $0.005 \%$ ) and contact powder (cumatetralil $0.75 \%$ ) respectively. Brodifacoum is a second-generation rodenticide that requires just a single dose while cumatetralil is a first-generation rodenticide that requires multiple exposures. The paraffin blocks were applied chiefly in humid places, for example, sewers and leakages around houses, while contact powder was used in identified rodent trails and burrows that are chiefly accessible only to rodents and not non-target species.

Environmental/ infrastructural intervention All valleys had infrastructural interventions accomplished by the city administration, that is, modification of open sewers (Fig. 2A, B \& C) and the construction of public squares (common paved spaces that are free of garbage and water puddles) and pavements, both roadways and sidewalks (Fig. 2C \& D), between early 2014 to the middle of 2015 which reduces rodents' sources of food (debris from standing water) and harbourage (burrow).

\section{Evaluation}

Track plates (TPs) This method has been previously validated as a proxy for rodent infestation and comprehensively described by Hacker et al. ${ }^{37}$ and Eyre et al. ${ }^{38}$. Weather-resistant lampblack was applied to $0.2 \times 0.2 \mathrm{~m}$ acetate sheet plates using a paint roller. The acetate plates dry off quickly ( $<5$ minutes) and allow detection of different types of marks left by rodents such as paw prints, tail marks and scratches. All TPs with any of these marks were recorded positive for rodent infestation. A total of 5 TPs were placed in a cross pattern for 2 nights at each sampling location throughout the campaigns.

The TPs were checked the morning after placement, identified by sampling location and photographed. Upon assigning $5 \times 5$-cell grids over each photograph, making 25 data points per plate, TPs were examined and scored by two independent trained examiners for rodent marks. Score discordances of $\geq 3$ cells between examiners were flagged and reviewed to achieve a consensus.

Environmental evaluation Rodents' access to water and food sources and harbourage for rodents were recorded at each sampling point by trained CCZ personnel using a modified US' CDC guidelines for interior and exterior rodent inspection forms ${ }^{36}$. Likewise, other information such as house ownership status and the presence of pets were also recorded at each sampling point.

\section{Statistical analysis}

To evaluate the expected decline and potential rebound in rodent population after the interventions, we used generalized linear mixed effects mode (GLMMs) with logistic link and binomially distributed error structure. Our response variable at each location and campaign was coded as 1 if at least one of the TPs at a given location was positive for rodent signs, or else coded as 0 . We treated valley and campaign as fixed effect factors and location as a random effect. 
Before testingt for a change in probability of rodent infestation (using TP positivity as a proxy) after interventions, we controlled for environmental variables that influence rodent infestation. We first used separate GLMMs to test for the relationships between the response variable and each of the following explanatory variables: presence of mud; soil \& vegetation; number of domestic animals; access to garbage, water \& food; proximity to sewer; and harbourage access i.e. presence of construction materials. Variables with $p$-values of $\leq 0.15$ from the single factor models were included in a provisional multifactor model, since opting for the more conventional level of 0.05 at this stage could fail to identify all the important variables ${ }^{39}$. The provisional model also included the interaction between campaign and valley to allow for any effects of interventions to vary across valleys. A mixed forward and backward stepwise model selection approach was used to determine the final model using the Akaike Information Criterion (AIC). We chose the most parsimonious model with $\triangle \mathrm{AIC}<2$ compared to the minimum as the final model ${ }^{40}$.

Within the final model, we tested the overall significance of any intervention using the Z-statistic $C / S E(C)$, where $C$ is the contrast between pre-intervention and post-intervention campaigns, i.e. average of the estimated main effects for campaigns 1 and 2 minus the average of the estimated main effects for campaigns 3 to 7, and $\operatorname{SE}(C)$ is the standard error of $C$. Similarly, we used a "difference of differences" contrast to test whether the size of the difference between pre-intervention and post-intervention campaigns differed significantly between the chemically treated valleys, 1 and 4, and the control valley, 2 .

All analyses were performed in R version 4.1.1 ${ }^{41}$, using the Ime4 (nAGQ = 9) ${ }^{42}$ and MuMIn (v1.43.17) ${ }^{43}$, ggpubr (v0.4.0) ${ }^{44}$, packages.

\section{Statement of ethical approval}

While there was no direct dealing with any live animal throughout this study, as rat activity/infestation level was obtained through indirect method using track plate. However, the Ethics Committee on the Use of Animals in Research (CEUA-CPqGM) of the Fundacao Oswaldo Cruz, Centro de Pesquisas Goncalo Moniz, Salvador- Bahia, Brazil gave the approval and permission to conduct research on rats with Project Numbers: 003/2012 and 019/2016. All participating residents (interviewees) involved in the environmental aspect of the study gave their informed consent before participation, and there was no interviewee below the age of 18 .

The entire study was conducted in accordance with the Brazilian laws regarding ethics in research.

\section{Results}

Population fluctuations across campaign per valley

We recorded rodent activity across both treatments pre and post-intervention (Fig. 3). The Z-statistic to test the overall significance of any intervention was $Z=-4.691 \quad(p<0.001)$ corresponding to significantly lower rat activity post-intervention. The Z-statistic to test the difference between the effects of the 
interventions with and without chemical treatment was $Z=-2.649(p=0.008)$, corresponding to a significantly smaller pre-intervention vs post-intervention difference in the valleys that were chemically treated. All three valleys, but especially the chemically treated valleys (1 \&4) had higher signs of rodent infestation before intervention than after intervention, with track plate positivity decreasing from $70-28 \%$ before and after interventions respectively. The overall peak infestation levels were recorded during the pre-intervention campaigns (Supplemental material 1), with a varied infestation patterns in $\mathrm{C} 1$ and $\mathrm{C} 2$ followed by a broad decline from $\mathrm{C} 3$ to $\mathrm{C} 5$ and then a somewhat similar increases from $\mathrm{C} 5$ to $\mathrm{C} 7$ across all valleys. The broad decline observed in the infestation level from C3 to C5 lasted for 10 months (Fig. 3). Also, the valley that received no chemical intervention showed the highest positivity level throughout the span of the study (Fig. 3 and Table 1), while the treatment valleys (valleys that received chemical intervention) rarely exceeded $40 \%$ positivity at any given time, especially after the intervention. A GLMM with the interaction between valley and campaign indicated that C5 (lowest infestation level) and C6 (onset of rodent repopulation, especially for valley 2) presented statistically different infestation level as compared to the remaining campaigns (Table 1). Also, campaigns 2, 3 and 5 in valley 2, and campaigns 3,5 through 7 in valley 4 had a statistically different rodent infestations level from the other observations (Table 1). 
Table 1

Summary of the generalized linear mixed-effects model with rodent infestation associated variables, and the interaction between valley and campaign to determine the recovery rate of rodents after the interventions.

\begin{tabular}{|llll|}
\hline & \multicolumn{2}{l}{ Plate positivity } & \\
\hline Predictors & Odds Ratios & Cl & $p$ \\
\hline (Intercept) & 0.65 & $0.30-1.42$ & 0.278 \\
\hline Valley [2] & 1.83 & $0.76-4.39$ & 0.176 \\
\hline Valley [4] & 0.18 & $0.07-0.45$ & $<0.001$ \\
\hline Campaign [2] & 1.31 & $0.63-2.74$ & 0.473 \\
\hline Campaign [3] & 0.81 & $0.40-1.65$ & 0.564 \\
\hline Campaign [4] & 0.43 & $0.21-0.89$ & $\mathbf{0 . 0 2 3}$ \\
\hline Campaign [5] & 0.21 & $0.10-0.46$ & $<0.001$ \\
\hline Campaign [6] & 0.28 & $0.13-0.63$ & $\mathbf{0 . 0 0 2}$ \\
\hline Campaign [7] & 0.36 & $0.17-0.79$ & $\mathbf{0 . 0 1 1}$ \\
\hline Access to Sewer [Yes] & 1.43 & $1.02-1.99$ & $\mathbf{0 . 0 3 6}$ \\
\hline Presence of Vegetation [Yes] & 1.90 & $1.09-3.28$ & $\mathbf{0 . 0 2 2}$ \\
\hline Presence of Mud [Yes] & 1.16 & $0.83-1.62$ & 0.387 \\
\hline Access to Garbage [Yes] & 1.45 & $1.05-1.99$ & $\mathbf{0 . 0 2 3}$ \\
\hline Valley [2] * Campaign [2] & 0.27 & $0.09-0.80$ & $\mathbf{0 . 0 1 9}$ \\
\hline Valley [4] * Campaign [2] & 1.60 & $0.48-5.34$ & 0.442 \\
\hline Valley [2] * Campaign [3] & 0.28 & $0.10-0.80$ & $\mathbf{0 . 0 1 7}$ \\
\hline Valley [4] * Campaign [3] & 3.47 & $1.15-10.45$ & $\mathbf{0 . 0 2 7}$ \\
\hline Valley [2] * Campaign [4] & 0.65 & $0.23-1.85$ & 0.420 \\
\hline Valley [4] * Campaign [4] & 2.96 & $0.97-9.07$ & 0.057 \\
\hline Valley [2] * Campaign [5] & 0.22 & $0.06-0.85$ & $\mathbf{0 . 0 2 8}$ \\
\hline Valley [4] * Campaign [5] & 3.85 & $1.12-13.24$ & $\mathbf{0 . 0 3 3}$ \\
\hline Valley [2] * Campaign [6] & 0.44 & $0.13-1.44$ & 0.174 \\
\hline Valley [4] * Campaign [6] & 9.80 & $2.82-34.05$ & $<0.001$ \\
\hline Valley [2] * Campaign [7] & 0.86 & $0.27-2.76$ & 0.799 \\
\hline
\end{tabular}




\begin{tabular}{|c|c|c|c|}
\hline & \multicolumn{3}{|c|}{ Plate positivity } \\
\hline Valley [4] * Campaign [7] & 5.91 & $1.80-19.46$ & 0.003 \\
\hline \multicolumn{4}{|l|}{ Random Effects } \\
\hline$\sigma^{2}$ & 3.29 & & \\
\hline$\tau_{00 \text { Location }}$ & 0.74 & & \\
\hline ICC & 0.18 & & \\
\hline $\mathrm{N}_{\text {Location }}$ & 117 & & \\
\hline Observations & 1317 & & \\
\hline
\end{tabular}

Factors associated with plate positivity

Seven variables (valley, campaign, treatment, presence of mud, \& vegetation, access to garbage and sewers) with $p$-values of $\leq 0.15$ from the initial analysis were considered for the generalized linear mixedeffects model (Supplemental material 2).

The final model retained six of these seven variables (valley, Campaign, mud, vegetation, sewers and access to garbage) with an AIC of 1661.8. The next best model had the same $\triangle \mathrm{AIC}$, but retained the entire seven variables. Presence of vegetation, access to garbage and sewers were positively associated with plate positivity-rodent infestation (Table 1). Additionally, from the Table 1 above, the fully treated valleyvalley 4 showed an overall significant reduction in infestation level after interventions (OR: 0.18 [0.07 0.45], $p=0.001$ ). Likewise, there was dissimilarity in infestation level between the treatment and control valleys before and after intervention, with valley 2 (control) having a significant lower infestation level during C2 (OR: 0.27 [0.09 - 0.80], $p=0.019$ ), and valley 4 recording a significant sustained reduction in infestation level during C5 \& C6 (Table 1).

\section{Discussion And Conclusion}

We reported a long-term decline in rodent infestation after interventions, which is different to previous studies $^{32,33}$ that only evaluated the rodent infestation level before and after intervention via a two sampling campaigns. Here, for the first time, we were able to systematically track the continuous dynamics in urban rodent infestation for a period of three years (the most comprehensive longitudinal study to our knowledge) and then describe any associated rodent repopulation even in a complex heterogeneous urban terrain like Salvador. We reported the onset of the population rebound around 10 months post-intervention, specifically commencing after C5 across the three valleys. Also, the fully treated valleys did not return to the pre-intervention infestation levels throughout the span of the study. Therefore, the effectiveness of the interventions and the time required for the onset of rodent repopulation in our study is longer than those previously reported by de Masi et al. ${ }^{32}$ in São Paulo, Brazil, and Lambropoulos et al. ${ }^{33}$ in Baltimore, USA, who both report that rodent repopulation take around 6 months 
to return to pre-intervention levels, using just two campaign regimes (before and after interventions) to evaluate rodent infestation levels.

We reported high rodent infestation before intervention in the three valleys. This might be due to the impoverished socioenvironmental conditions of the study area such as open sewage, improper garbage disposal and deficient garbage collection services and even overcrowded apartments, particularly before the interventions. These conditions have been reported to provide sufficient water, food and harbourage sources that encourage the onward proliferation of rodents in any given environment ${ }^{1,11,32,45,46}$.

Over the years, the main strategy used for household rodent infestation management has been the application of chemical rodenticides. Although this method is relatively easy to execute, it requires consistent investment and has a limited success-rate, with the added risk of inadvertently increasing rodents' chances of contracting zoonoses ${ }^{47}$, while allowing population rebound and selective neophobia resistance among the residual population ${ }^{3,48}$. However, the overall significant reduction seen in rat infestation post-intervention (Z-statistics), and reduction in the degree of infestation recorded in $\mathrm{C} 4$ and $\mathrm{C} 5$ across all valleys suggests that chemical and infrastructural interventions evaluated here may be critical in reducing rodent infestation. Nevertheless, this might not be an absolute solution to the problem, considering there was a significantly smaller reduction in plate positivity post-intervention in the chemical treated valleys, than the chemicl control valley (Z-statistic for testing the difference in the effect of intervention across valleys), which might be due to varying degree of environmental confoundings across the valleys. However, the inability of the valleys to completely attain the pre-intervention infestation level after the chemical and infrastructural interventions substantiates the fact that IPM-approaches are more reliable in the long-term management of rodent infestation than the application of a single control method $^{49-51}$.

Looking more closely at the combination of chemical and environmental control, a considerable reduction in rodent infestation was observed after the chemical intervention (C3 and beyond); similarly, we observed a substantial U-shaped recovery from the lowest infestation point (C5) across all the study valleys (Table 1, Fig. 3). This seems to indicate that chemical intervention alone may not be sufficient for controlling rodent infestation especially in a highly rodent infested environments. This contrasts with previous findings in the Bahamas ${ }^{10}$, where a reduction was observed in the rodent infestation proxy (sightings reported by locals). However, the difference in the nature of the response variables used in the studies might affect and hinder comparisons, particularly given the limitations of using rodent sightings to estimate infestation level. In contrast, the significant reduction in rodent infestation observed in valley 2 between $\mathrm{C} 2$ and $\mathrm{C} 3$ (before and during the infrastructural environmental interventions) could indicate environmental modification as an important component in rodent infestation management. The eventual population recovery reported in valley 2 also indicates that environmental intervention alone is aswell not sufficient for controlling rodent populations in urban settings ${ }^{52}$. Nevertheless, it reduces the carrying capacity of the environment by denying rodents the access to resources ${ }^{13}$. 
Based on our model, in addition to the pre-treatment conditions, household accessibility to sewer had the highest association with rodent infestation level which may be as a result of the rodents being able to obtain their major source of nourishment from the sewer. Additionally, households with close proximity to sewers had higher percentage of rodent infestation (Supplemental material 3a). Brooks ${ }^{53}$ puts that rodents flourish in this type of environment since it provides them with water and garbage that are daily thrown into the sewer.

Likewise, other factors reported as independent risk factors for rodent infestation were the presence of mud, vegetation and access to garbage (Supplemental material $3 b-d$ ) as these provide an alternative food source for rodents ${ }^{46}$. These conditions are similar to those earlier reported to be positively associated with rodent infestation by Costa et al. ${ }^{49}$ except for the mud. Nevertheless, the pre-treatment condition of valley 4 being the lowest independent risk factor associated with rodent infestation in this study might signify that the valley has a relatively better socioeconomic condition or practice better hygiene than the other valleys, thereby lowering rodents' source of food, water or harbourage.

Although we were able to collate practical data on rodent infestation in a longitudinal study divided over 7 campaigns for almost three years in a difficult urban environment, we were unable to survey a complete control valley (a valley without chemical and infrastructural intervention). Our original plan was to compare three independent valleys with two valleys having both chemical and infrastructural intervention and the other without any intervention. However, our original research plan was altered since the city administration decided to implement an infrastructural intervention in all the three valleys. While our result is useful in shaping the holistic impact of chemical and structural interventions both as a separate entity and a whole, further investigations using a completely negative valley (without any form of intervention) should yield a clearer result.

In conclusion, our result shows that IPM-approaches are a more reliable and lasting way of solving rodent problems than just the application of a single method. These findings should be useful in guiding the policymakers, non-governmental organizations, ecologists, rodent pest control organizations and others interested in rodent control on effective long-term rodent control programs. Lastly, the incorporation of this approach should assist in combating the proliferation of rodents in the urban low-income communities, while also aiding the indirect control of vector-borne zoonoses in these urban low-income environments.

\section{Declarations}

Funding details: This work was supported by CNPq-TWAS (Process No.148306/2017-9); the Oswaldo Cruz Foundation and Secretariat of Health Surveillance, Brazilian Ministry of Health, the National Institutes of Health of the United States (grant numbers F31 Al114245, R01 Al052473, U01 Al088752, R01 TW009504 \& R25 TW009338); the Wellcome Trust (102330/Z/13/Z) and the Fundação de Amparo a Pesquisa do Estado da Bahia (FAPESB/JCB0020/2016). Open access funding provided by Swedish University of Agricultural Sciences. 
E.M.S. acknowledges CNPq (Process No. 465767/2014-1) and CAPES (Process No. 23038.000776/201754) for INCT IN-TREE financial support.

Lastly, A.M.A. was a CNPq-TWAS Ph.D. fellow, while F.N.S. \& C.G.Z. were FAPESB Ph.D. fellows at the time of this study.

Acknowledgments: The authors appreciate Salvador Prefeitura and the Center for Control of Zoonoses (Centro de Controle de Zoonoses - CCZ), Salvador-Bahia for the implementation of the interventions at the study area. Also, the authors are grateful to the staff of $\mathrm{CCZ}$ for their assistance during the sample collection likewise the residents of Pau da Lima for their cooperation during the study.

Disclosure statement: No potential conflict of interest was reported by the authors.

Data availability statement: All datasets and codes used during this study are available in Zenodo under Creative Commons 4.0 license, accessible through https://doi.org/10.5281/zenodo.5796022 (Awoniyi et al., 2021).

\section{Authors' contributions:}

Conceptualization:A.M.A., C.V.V., F.C. \& H.K.

Data curation: C.V.V., F.N.S., K.P.H., T.C.P., C.L.M., M.C.S., A.C.P. \& F.C.

Formal analysis:A.M.A., F.N.S., C.G.Z., P.J.D., F.C.\& H.K.

Funding acquisition:M.B., A.I.K., P.J.D., M.G.R., J.E.C., F.C. \& H.K.

Methodology:A.M.A., C.V.V., F.N.S., C.G.Z., K.P.H., T.C.P., M.B., A.I.K., P.J.D., M.G.R., J.E.C., E.M.S., F.C. \& H.K.

Project administration \& resources:M.B., A.I.K., P.J.D., M.G.R., J.E.C., F.C. \& H.K.

Supervision:M.B., E.M.S., F.C. \& H.K.

Writing-original draft:A.M.A.

Writing-review \& editing:A.M.A., C.G.Z., K.P.H., M.B., P.J.D., J.E.C., E.M.S., F.C.\& H.K.

\section{References}

1. Panti-May, J. A. et al. A Two-Year Ecological Study of Norway Rats (Rattus norvegicus) in a Brazilian Urban Slum. PLOS ONE, 11(3), 1-12. https://doi.org/10.1371/journal.pone.0152511 (2016)

2. Himsworth, C. G., Parsons, K. L., Feng, A. Y. T., Kerr, T., Jardine, C. M. \& Patrick, D. M. A mixed methods approach to exploring the relationship between Norway rat (Rattus norvegicus) abundance and 
features of the urban environment in an inner-city neighborhood of Vancouver, Canada. PLOS ONE, 9(5). https://doi.org/10.1371/journal.pone.0097776 (2014)

3. Lambert, M. S., Quy, R. J., Smith, R. H. \& Cowan, D. P. The effect of habitat management on homerange size and survival of rural Norway rat populations. Journal of Applied Ecology, 45(6), 17531761. https://doi.org/10.1111/j.1365-2664.2008.01543.x (2008)

4. Meerburg, B. G., Singleton, G. R. \& Kijlstra, A. Rodent-borne diseases and their risks for public health (Vol. 7828). https://doi.org/10.1080/10408410902989837 (2009)

5. Buckle, A. \& Smith, R. Rodent pests and their control: 2nd edition. In Rodent Pests and Their Control: 2nd Edition. (2015)

6. Byers, K. A., Lee, M. J., Patrick, D. M. \& Himsworth, C. G. Rats about town: A systematic review of rat movement in urban ecosystems. Frontiers in Ecology and Evolution, 7(JAN), 1-12. https://doi.org/10.3389/fevo.2019.00013 (2019)

7. Carvalho-Pereira, T. et al. The helminth community of a population of Rattus norvegicus from an urban Brazilian slum and the threat of zoonotic diseases. Parasitology, 145(6), 797-806. https://doi.org/10.1017/S0031182017001755 (2018)

8. Costa, F. et al. Patterns in Leptospira shedding in Norway rats (Rattus norvegicus) from Brazilian slum communities at high risk of disease transmission. PLoS Neglected Tropical Diseases, 9(6), 114. https://doi.org/10.1371/journal.pntd.0003819 (2015)

9. Parsons, M. H. et al. Rats and the COVID-19 pandemic: Early data on the global emergence of rats in response to social distancing. MedRxiv, 2020.07.05.20146779. https://doi.org/10.1101/2020.07.05.20146779 (2020)

10. Awoniyi, Adedayo M. et al. Effect of chemical and sanitary intervention on rat sightings in urban communities of New Providence, the Bahamas. SN Appl. Sci. 3, 495. https://doi.org/10.1007/s42452-021-04459-x (2021a)

11. Costa, F. et al. Influence of Household Rat Infestation on Leptospira Transmission in the Urban Slum Environment. PLoS Neglected Tropical Diseases, 8(12). https://doi.org/10.1371/journal.pntd.0003338 (2014)

12. Khalil, H. et al. Poverty, sanitation, and Leptospira transmission pathways in residents from four Brazilian slums. PLoS Neglected Tropical Diseases, 15(3), 1-15. https://doi.org/10.1371/journal.pntd.0009256 (2021)

13. Zeppelini, C. G. et al. Demographic drivers of Norway rat populations from urban slums in Brazil. Urban Ecosystems. https://doi.org/10.1007/s11252-020-01075-2 (2020)

14. United Nations -UN. World Urbanization Prospects: The 2018 Revision, Available: https://www.un.org/development/desa/en/news/population/2018-revision-of-world-urbanizationprospects.html. Accessed 24 December 2020 (2018)

15. United Nations UN-SDG. Sustainable Development Goals: Make cities and human settlements inclusive, safe, resilient and sustainable, Available: https://unstats.un.org/sdgs/report/2019/goal- 
11/\#: :text=The\%20absolute\%20number\%20of\%20people,Southern\%20Asia\%20(227\%20million). Accessed 24 December 2020 (2018)

16. Russell, J. C., Towns, D. R. \& Clout, M. N. Review of rat invasion biology: Implications for island biosecurity. Science for Conservation, (286), 1-53. (2008)

17. Minter, A. et al. Optimal Control of Rat-Borne Leptospirosis in an Urban Environment. Frontiers in Ecology and Evolution, 7(June), 1-10. https://doi.org/10.3389/fevo.2019.00209 (2019)

18. Mathur, R. P. Effectiveness of various rodent control measures in cereal crops and plantations in India. In: Leirs H. and Schockaert E. ed. Proceedings of the International Workshop on Rodent Biology and Integrated Pest Management in Africa, 21-25 October 1996, Morogoro, Tanzania. Belgian Journal of Zoology, 127 (supplement 1), 137-144 (1997)

19. Pascal, M., Siorat, F., Lorvelec, O., Yésou, P. \& Simberloff, D. A pleasing consequence of Norway rat eradication: two shrew species recover. Diversity and Distributions, 11, 193-198. https://doi.org/10.1111/j.1366-9516.2005.00137.x (2005)

20. Singleton, G. R., Hinds, L. \& Leirs, H. Ecologically-based management of rodent pests. Australian Centre for International Agricultural Research, (ACIAR Monograph 59), 494. (1999)

21. Sullivan, L. M. Roof rat control around homes and other structures. Cooperative Extension Bulletin AZ1280, 1-6. (2002)

22. Childs, J. E. Size-dependent predation on rats (Rattus norvegicus) by house cats (Felis catus) in an urban setting. Journal of Mammology, 67(1), 196-199 (1986)

23. Davis, D. E. The characteristics of rat populations. Quart. Rev. Biol. 28, 373-401. https://doi.org/10.1086/399860 (1953)

24. Glass, G. E. et al. Trophic Garnishes: Cat-Rat Interactions in an Urban Environment. PLoS ONE 4(6):e5794, https://doi.org/10.1371/journal.pone.0005794 (2009)

25. Lenton, G.M. Biological control of rats by owls in oil palm and other plantations. Biotrop Special Publication No. 12, 87-94. (1980)

26. Smith, R.H. \& Meyer, A.N. Rodent controlmethods: Non-chemical and non-lethal chemical, with special reference to food stores. In Buckle, A., \& Smith, R. (Eds.), Rodent pests and their control (2nd ed., pp. 81-101). CABI International, Wallingford, Oxon UK. ISSN-13: 9781845938178 (2015)

27. Oyedele, D. T., Sah, S. A. M., Kairuddin, L. \& Ibrahim, W. M. M. W. Range Measurement and a Habitat Suitability Map for the Norway Rat in a Highly Developed Urban Environment. Tropical Life Sciences Research 26(2): 27-44 (2015)

28. Hansen, N., Hughes, N. K., Bryom, A. E. \& Banks, P. B. Population recovery of alien black rats Rattus rattus: A test of reinvasion theory. Austral Ecology 45: 291-304. https://doi.org/10.1111/aec.12855 (2020)

29. Awoniyi, A. Michael. et al. Using Rhodamine B to assess the movement of small mammals in an urban slum. Methods in Ecology and Evolution, 12(11), 2234-2242. https://doi.org/10.1111/2041210X.13693 (2021b) 
30. Glass, G. E., Klein, S. L., Norris, D. E. \& Gardner, L. C. Multiple paternity in urban Norway rats: extended ranging for mates. Vector-Borne and Zoonotic Diseases, 16(5): 342-248, https://doi.org/10.1089/vbz.2015.1816 (2016)

31. Buckle, A.P. \& Eason, C.T. Rodent control methods: Chemical. In Buckle, A., \& Smith, R. (Eds.), Rodent pests and their control (2nd ed., pp. 81-101). CABI International, Wallingford, Oxon UK. ISSN-13: 978 1845938178 (2015)

32. de Masi, E., Pedro, J. V., Maria, T. P. Evaluation on the effectiveness of actions for controlling infestation by rodents in Campo Limpo region, São Paulo Municipality, Brazil Access details : Access Details : [ subscription number 913003116 ]. International Journal of Environmental Health Research, 19(4), 291-304. https://doi.org/10.1080/09603120802592723 (2009)

33. Lambropoulos, A. S. et al. Rodent control in urban areas - An interdisciplinary approach. Journal of Environmental Health, 61, 12-17 (1999)

34. Reis, R. B. et al. Impact of Environment and Social Gradient on Leptospira Infection in Urban Slums. PLoS Neglected Tropical Diseases, 2(4), 11-18. https://doi.org/10.1371/journal.pntd.0000228 (2008)

35. Instituto Brasileiro de Geografia e Estatistica (IBGE). Accessed 15 November 2019 (2010)

36. CDC. Integrated pest management: conducting urban rodent surveys. Centers for Disease Control and Prevention- Atlanta: US Department of Health and Human Services (2006)

37. Hacker, K. P. et al. A comparative assessment of track plates to quantify fine scale variations in the relative abundance of Norway rats in urban slums. Urban Ecosystems, 19(2), 561-575. https://doi.org/10.1007/s11252-015-0519-8 (2016)

38. Eyre, M. T. et al. A multivariate geostatistical framework for combining multiple indices of abundance for disease vectors and reservoirs: A case study of rattiness in a low-income urban Brazilian community: A multivariate geostatistical framework for combining multiple ind. Journal of the Royal Society Interface, 17(170), 1-21. https://doi.org/10.1098/rsif.2020.0398 (2020)

39. Bursac, Z., Gauss, C. H., Williams, D. K. \& Hosmer, D. W. Source Code for Biology and Purposeful selection of variables in logistic regression. 8, 1-8. https://doi.org/10.1186/1751-0473-3-17 (2008)

40. Burnham, K. P. \& Anderson, D. R. Model selection and multimodel inference: A practical informationtheoretic approach. New York: Springer. (2002)

41. R Core Team. R: A language and environment for statistical computing. R Foundation for Statistical Computing, Vienna, Austria. URL https://www.R-project.org (2019)

42. Bates, D., Maechler, M., Bolker, B. \& Walker, S. Fitting Linear Mixed-Effects Models Using Ime4. Journal of Statistical Software, 67(1), 1-48. https://doi.org/10.18637/jss.v067.i01 (2015)

43. Barton, K. MuMIn: Multi-Model Inference. R package version 1.43.17. https://CRAN.Rproject.org/package=MuMIn (2020)

44. Kassambara A. ggpubr: 'ggplot2' Based Publication Ready Plots. R package version 0.4.0. https://CRAN.R-project.org/package=ggpubr (2020) 
45. Richardson, J. L. et al. Using fine-scale spatial genetics of Norway rats to improve control efforts and reduce leptospirosis risk in urban slum environments. Evolutionary Applications, 10(4), 323-337. https://doi.org/10.1111/eva.12449 (2017)

46. Santos, N. D. J., Sousa, E., Reis, M. G., Ko, A. I. \& Costa, F. Rat infestation associated with environmental deficiencies in an urban slum community with high risk of leptospirosis. 33(2), 1-13. https://doi.org/10.1590/0102-311X00132115 (2017)

47. Murray, M.H. \& Sanchez, C.A. Urban rat exposure to anticoagulant rodenticides and zoonotic infection risk. Biol Lett, 17: 20210311. https://doi.org/10.1098/rsbl.2021.0311 (2021)

48. Parsons, M. H., Banks, P. B., Deutsch, M. A., Corrigan, R. F. \& Munshi-South, J. Trends in urban rat ecology: A framework to define the prevailing knowledge gaps and incentives for academia, pest management professionals (PMPs) and public health agencies to participate. Journal of Urban Ecology, 3(1), 1-8. https://doi.org/10.1093/jue/jux005 (2017)

49. Costa, F. et al. Household rat infestation in urban slum populations: Development and validation of a predictive score for leptospirosis Household rat infestation in urban slum populations : Development and validation of a predictive score for leptospirosis. PLoS Neglected Tropical Diseases, 15(3). https://doi.org/10.1371/journal.pntd.0009154 (2021)

50. Mwanjabe, P. S. \& Leirs, H. An early warning system for IPM-based rodent control in smallholder farming systems in Tanzania. In: Leirs, H., \& Schockaert, E., ed., Proceedings of the International Workshop on Rodent Biology and Integrated Pest Management in Africa, 21-25 October 1996, Morogoro, Tanzania. Belgian Journal of Zoology, 127 (supplement 1), 4-58. (1997)

51. Richards, C. G. J. R. \& Buckle, A. P. Towards integrated rodent pest management at the village level. In: Richards, C. G. J. R. \& Ku, T. Y., ed., Control of mammal pests. London, Taylor and Francis, 293312 (1987)

52. Masi, E. Socioeconomic and environmental risk factors for urban rodent infestation in Sao Paulo, Brazil. Journal of Pest Science, 83(3), 231-241. https://doi.org/10.1007/s10340-010-0290-9 (2010)

53. Brooks, Joe E. Methods of Sewer Rat Control, Proceedings of the 1st Vertebrate Pest Conference. https://digitalcommons.unl.edu/vpcone/17. Accessed 20 August 2021 (1962)

\section{Figures}


A

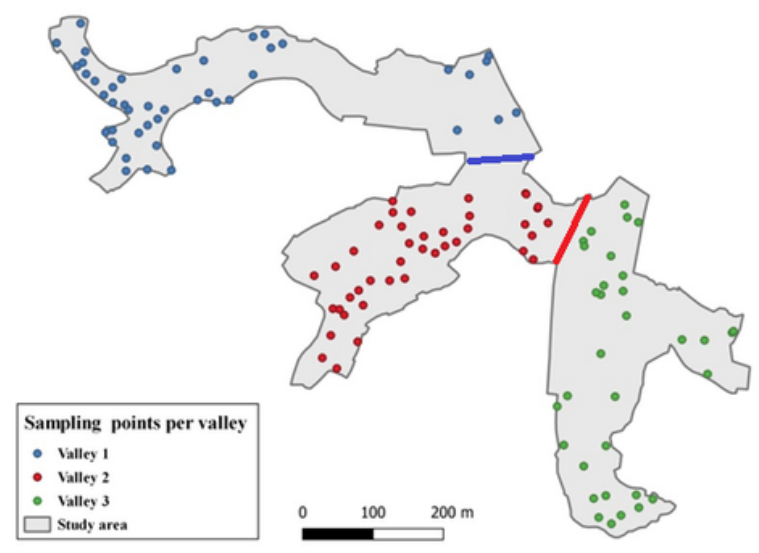

B

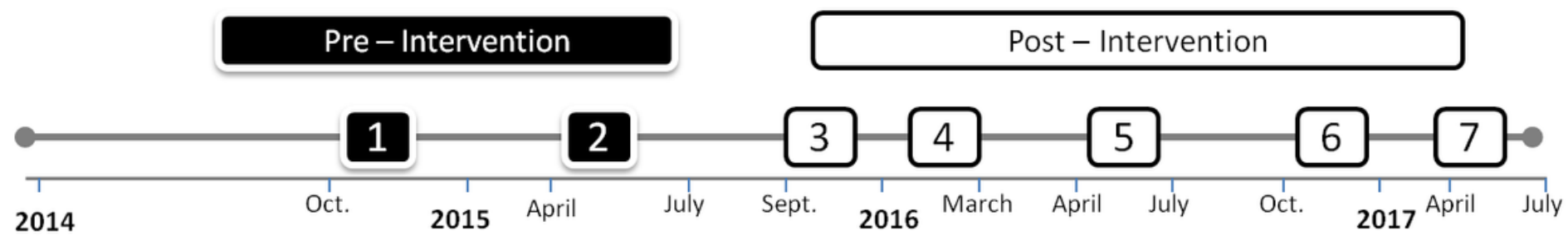

Figure 1

A) The distribution of the sampling points in the three valleys used in Pau da Lima. B) Breakdown of the study timeline for rodent infestation surveys from campaign 1 to 7 . 


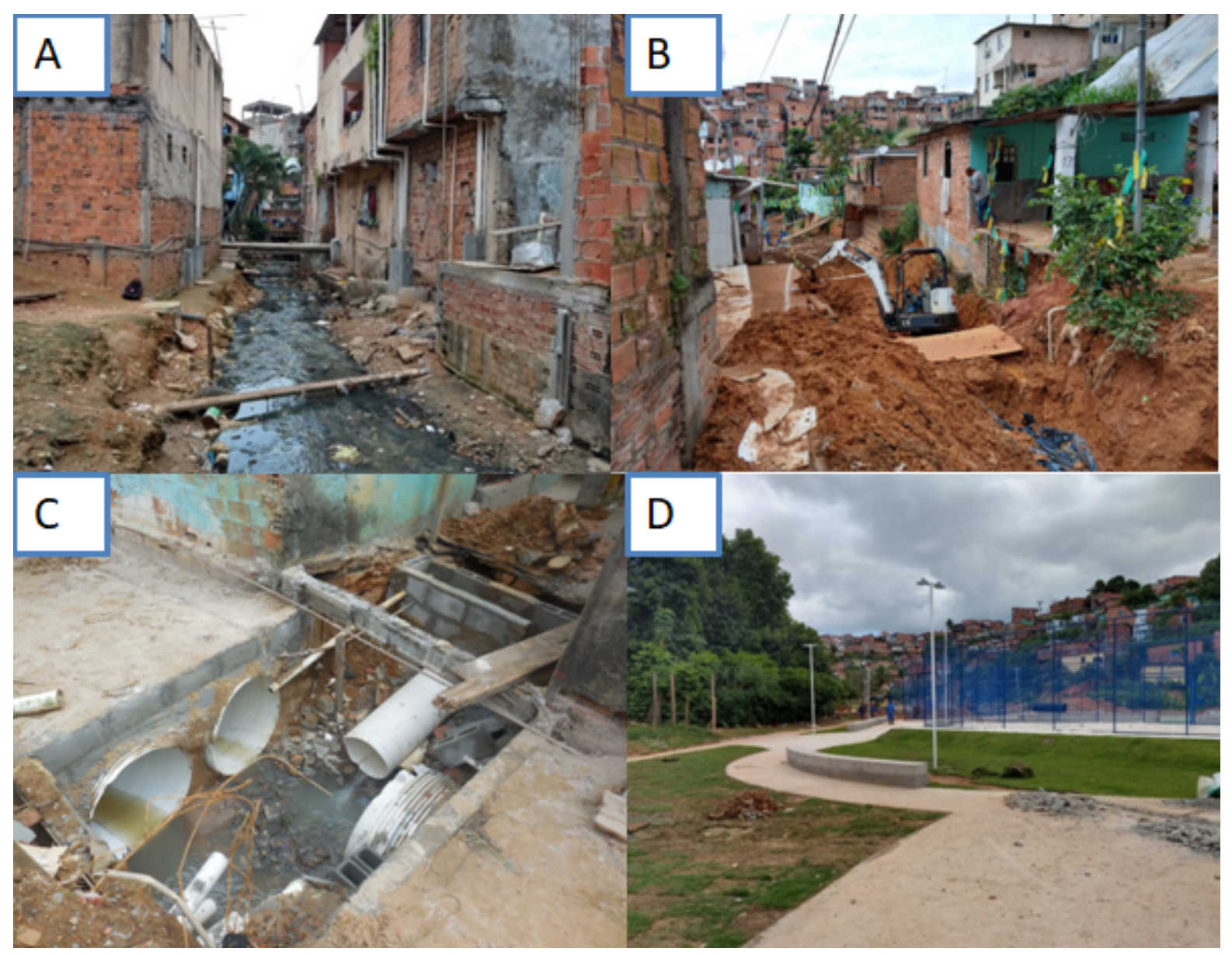

Figure 2

A \& B) An open sewer between households in the study area, C \& D) The study area undergoing environmental modification i.e. channeling of the drainage into a major junction, and the construction of community square, roadway and sidewalk. 


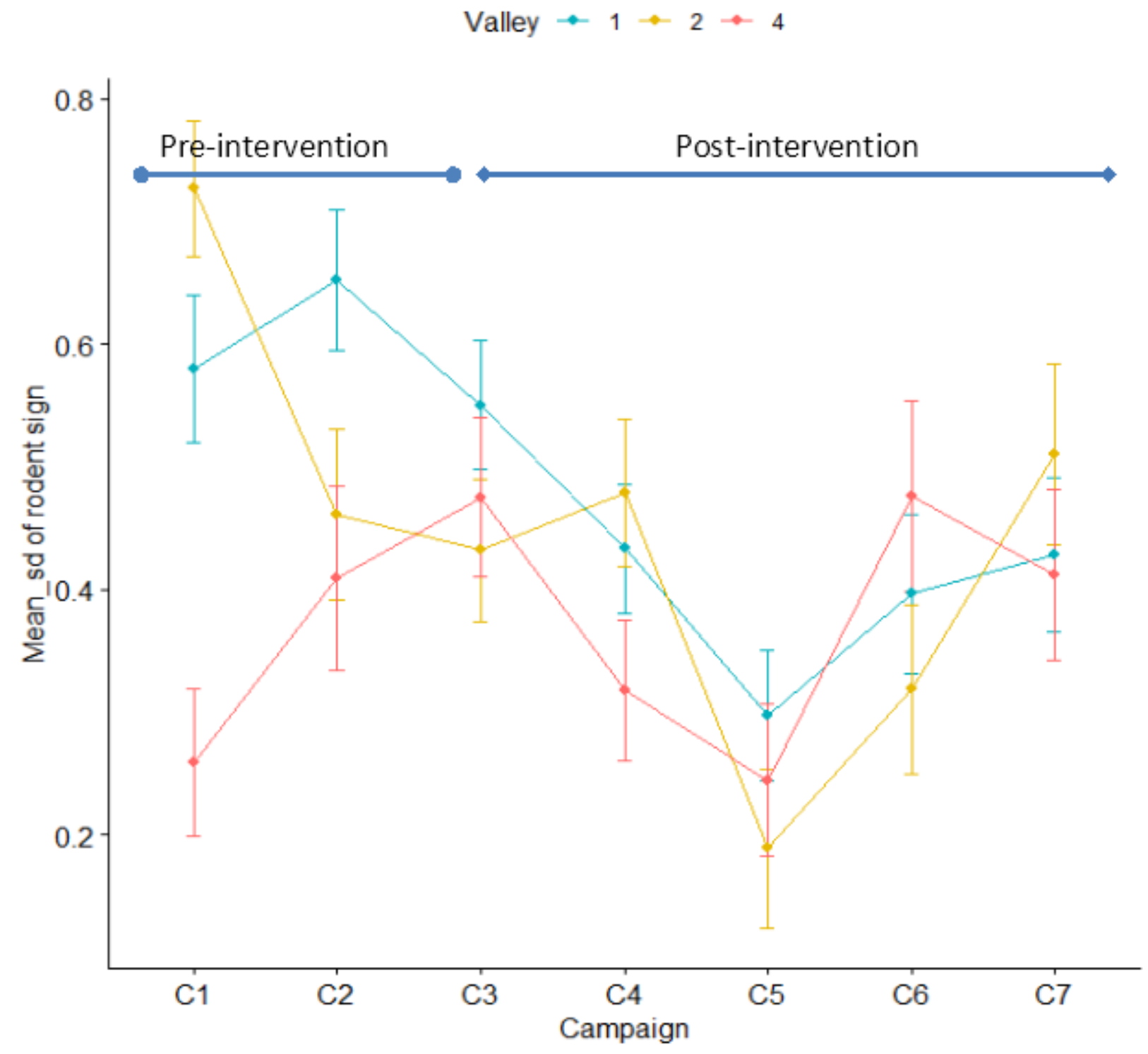

Figure 3

Mean with standard deviation of rodent infestation by campaign and valley (valley 1 - blue, valley 2 yellow \& valley 4 -red colour respectively)

\section{Supplementary Files}

This is a list of supplementary files associated with this preprint. Click to download.

- SciRepSupplementalmaterials.docx 